\title{
Paresia bilateral assimétrica de nervo troclear associada a trombose de seio transverso pós-otite - relato de caso
}

\author{
Asymmetricbilateraltrochlearpalsyand transversesinus thrombosisafterotitis-casereport
}

\author{
Ana Tereza Ramos Moreira ${ }^{1}$ \\ Hilton Iran Ruthes ${ }^{2}$ \\ Daniel Roncaglio Guerra ${ }^{3}$ \\ Ana Cristina Alvarez de Carvalho ${ }^{4}$
}

\begin{tabular}{|l|}
\hline RESUMO \\
\hline Os autores descrevem um caso de otite média aguda pós-perfuração de \\
membrana timpânica, que evoluiu com trombose de seio transverso \\
esquerdo, paresia facial central à direita e paresia troclear bilateral \\
assimétrica. O exame oftalmológico mostrou hipofunção do OS e \\
hiperfunção do OI nos dois olhos, mais intensas no olho direito. O sinal \\
de Bielchowsky era positivo à direita e negativo à esquerda. A acuidade \\
visual estava preservada, além de ausência de papiledema à fundoscopia. \\
A arteriografia cerebral revelou unicamente trombose do seio transver- \\
so à esquerda. O tratamento instituido foi antibioticoterapia via oral e \\
cumarínico. Após seis meses de evolução a diplopia persistia apenas \\
em infralevoversão, porém persistia a paresia facial central à direita. \\
Não se encontrou na literatura relato semelhante ao descrito.
\end{tabular}

Descritores: Paresia; Nervo troclear/patologia; Trombose dos seios intracranianos; Otite; Relato de caso

\section{INTRODUÇ̃̃O}

A trombose de seio transverso é uma doença rara, sendo quase exclusivamente uma complicação de otite média, mastoidite, ou ambos. Os agentes etiológicos incluem: Proteus sp, E. coli, S. aureus, e anaeróbios. Os sintomas consistem geralmente de cefaléia severa, persistente, unilateral, fronto-occipital, seguida por náuseas e vômitos e, menos comumente, por diplopia e vertigem. Otalgia e otorréia frequentemente precedem estes sintomas em algumas semanas. Outros sinais e sintomas incluem febre, papiledema, observado em mais da metade dos casos. Sinais neurológicos focais são incomuns, mas pode ocorrer paralisia do VI nervo ipsilateral ${ }^{(1-2)}$.

A investigação pode ser feita através dos seguintes métodos diagnósticos: punção lombar, tomografia computadorizada, angiografia, sendo esta última considerada o melhor método para a demonstração de oclusão de seio transverso ${ }^{(1)}$. Autópsia também pode ser esclarecedora nos casos em que ocorre morte do paciente antes de um diagnóstico preciso ${ }^{(3)}$.

O presente estudo descreve um caso de trombose de seio transverso decorrente de otite média aguda, cursando com paresia facial central e paresia bilateral assimétrica do nervo troclear.

\section{RELATO DO CASO}

Paciente masculino, 30 anos, branco, encaminhado ao serviço de Oftalmologia para avaliação de diplopia. Três meses antes apresentou

Chefe do serviço de oftalmologia do Hospital de Clínicas da Universidade Federal do Paraná. 
episódio de otite média aguda decorrente de perfuração da membrana timpânica do ouvido direito por objeto pontiagudo. Após duas semanas de evolução, apresentou cefaléia frontal contínua de leve intensidade e diplopia, que melhorava com a inclinação da cabeça sobre o ombro esquerdo. Ausência de história pregressa de doenças crônicas, trauma, etilismo ou tabagismo.

Ao exame apresentou como dados relevantes: paresia facial central à direita, perfuração de membrana timpânica à direita, acuidade visual de 20/20 AO, biomicroscopia e fundoscopia normais. Havia hipofunção do OSD -2, hiperfunção do OID +2, Hipofunção do OSE -1 e hiperfunção do OIE +1. Em infraversão, o paciente apresentava uma esotropia discreta (Tabela 1). Sinal de Bielchowsky positivo à direita e negativo à esquerda (Anexo 1). O paciente estava afebril e ao exame não demonstrou sinais de irritação meningo-radicular.

Apresentou exames laboratoriais (exceto líquor) e a tomografia axial computadorizada de crânio normais. O líquor mostrou sinais de inflamação discreta. A arteriografia cerebral revelou trombose de seio transverso à esquerda (Anexo 2)

Inicialmente a otite havia sido tratada com amoxicilina $500 \mathrm{mg}$ via oral de $8 / 8$ horas e corticóide tópico. Devido ao resultado da arteriografia instituiu-se tratamento com cumarínico via oral, femprocumona (Marcoumar $\left.{ }^{\circledR}\right)$. O controle da anticoagulação foi realizado através de medidas seriadas de TAP com RNI.

Após 6 meses de evolução, referia melhora importante da diplopia, persistindo apenas HT E/D de $0,5 \Delta$ em infralevoversão. Persistia também a paresia facial central à direita, sendo o restante do exame normal.

\section{COMENTÁRIOS E DISCUSSÃO}

Otite média aguda ou crônica pode ter complicações graves como meningite, abscesso cerebral, trombose de seio transverso, abscesso cerebelar e, mais raramente, abscesso extradural e subdural. Os sintomas mais relacionados aos casos complicados de otite média incluem cefaléia intensa, febre diária, otalgia com ou sem otorréia, mal estar geral, fotofobia e vertigem ${ }^{(4)}$.

A complementação diagnóstica de uma otite média que evolui com perfuração da membrana timpânica, persistência de otorréia e presença dos outros sintomas característicos de gravidade, se faz necessária através de exames de imagem como tomografia axial computadorizada de crânio (TAC) e

\begin{tabular}{|c|c|c|c|c|}
\hline \multicolumn{5}{|c|}{$\begin{array}{l}\text { Tabela 1. Resultados do "cover-uncover" teste. Posições } \\
\text { cardeais do primárias e com a cabeça inclinada }\end{array}$} \\
\hline & HT E/D 12১ & XT $4 \Delta$ & HT D/E $25 \Delta$ & \\
\hline \multirow{2}{*}{\begin{tabular}{|c} 
HT D/E \\
$12 \Delta$
\end{tabular}} & Orto & HT D/E 4s & HT D/E 25 & \multirow[t]{2}{*}{ ORTO } \\
\hline & $\mathrm{HT}$ E/D $4 \Delta$ & $\begin{array}{l}\text { HT D/E } 15 \Delta \\
\text { ET } 8 \Delta\end{array}$ & HT D/E $30 \Delta$ & \\
\hline
\end{tabular}

arteriografia. Os abscessos cerebrais decorrentes de otite são habitualmente demonstrados pela TAC, enquanto as tromboses de seios cerebrais podem ser diagnosticadas a partir de imagens em AP, perfil e oblíquo reveladas por arteriografia, que é o método radiológico complementar de escolha. Ainda assim é preciso fazer a punção lombar para análise do líquido cefalorraquidiano antes de se afastar meningite associada ou hipertensão intracraniana ${ }^{(3)}$.

Apesar da trombose de seios da dura máter pós-infecção ter sido um achado comum antes do advento dos antibióticos, existem relatos na literatura que comprovam a ocorrência deste tipo de complicação na vigência de mastoidite, sinusite ou otite ainda nos dias atuais.

A trombose do seio transverso, situação raramente encontrada, consiste em complicação praticamente exclusiva de otite média aguda ou crônica e/ou de mastoidite. Inicialmente, os pacientes com este quadro apresentam inúmeros sinais e sintomas: náuseas, vômitos, diplopia, diminuição da acuidade visual, cefaléia severa holocraniana ou occipitofrontal, localizada do mesmo lado da infecção.

Em contraste com a trombose do seio cavernoso, cuja característica é a manifestação aguda, a trombose do seio transverso geralmente tem evolução sub-aguda, com persistência dos sintomas por várias semanas antes de se tornar incômoda o suficiente para que o paciente procure auxílio médico ${ }^{(3)}$.

O tratamento baseia-se em antibioticoterapia direcionada para os principais patógenos envolvidos em otites crônicas ou mastoidite: Proteus sp, S. Aureus, anaeróbios e E.Coli. Dificilmente o tratamento cirúrgico é a escolha. A opção por terapia anticoagulante é controversa na literatura. Segundo Glassock, 1980, anticoagulação deve ser administrada a todos os pacientes com trombose de seio transverso ${ }^{(2)}$, já Southwick, 1986, alerta para a maior ocorrência de hemorragia cerebral na vigência do uso de anticoagulantes. Na evidência de infecção otológica e febre persistente apesar do uso apropriado de antibióticos, a trombose de seio transverso deve ser sempre considerada como hipótese diagnóstica. Sinais neurológicos podem estar presentes corroborando para o possível envolvimento de nervos cranianos. Dentre estes, os mais acometidos são o VI, o III e o IV nervos.

As paralisias ou paresias do IV nervo craniano podem ser adquiridas ou congênitas. As adquiridas são em geral unilaterais e causadas por trauma crânio-encefálico ou doença vascular (diabetes e hipertensão). Os tumores e aneurismas são causas raras de paralisia do nervo troclear. Em geral, um terço dos pacientes acometidos não têm etiologia determinada. Ao exame oftalmológico inicial comumente são encontrados hipertropia, limitação da depressão em adução, diplopia vertical e inclinação da cabeça para o lado oposto ao músculo oblíquo superior paralisado ${ }^{(5)}$.

A hipertropia resulta do enfraquecimento do músculo oblíquo superior, frequentemente com hiperfunção do seu antagonista ipsilateral, o músculo oblíquo inferior, e torna-se 
mais evidente quando a cabeça é inclinada para o ombro correspondente ao lado do músculo afetado, manobra conhecida como sinal de Bielchowsky positivo.

$\mathrm{Na}$ literatura, encontram-se vários relatos de associação da paralisia do nervo troclear com trombose de seio cavernoso. Segundo Walsh, 1957, se houver paralisia de III ou IV nervo na vigência de trombose de seio transverso, deve ser suspeitada trombose de seio cavernoso ou meningite basilar ${ }^{(6)}$.

O diagnóstico de uma paresia ou paralisia bilateral assimétrica do nervo troclear é normalmente difícil, pois as alterações motoras causadas pela paresia do olho mais afetado podem mascarar os sinais de paresia do olho menos afetado, e induzir um falso diagnóstico de paresia unilateral do músculo oblíquo superior. Essa dificuldade é devida ao fenômeno da paresia inibicional de Chavasse, na qual ocorre limitação da elevação do olho menos afetado. A hiperfunção do músculo reto inferior direito e a paresia inibicional de Chavasse de seu antagonista (RS esquerdo), limitam ou impedem a elevação do olho esquerdo quando se inclina a cabeça para a esquerda, mascarando o sinal de Bielchowsky. Uma vez reestabelecido o equilíbrio do grupo esquerdo por meio de cirurgia, todos aqueles secundarismos desaparecem, e o sinal de Bielchowsky torna-se positivo para o lado esquerdo ${ }^{(7)}$.

No paciente deste relato não foi necessário tratamento cirúrgico, uma vez que o restabelecimento da função muscular se deu espontaneamente. A paresia central do VII nervo craniano à direita encontrada no paciente avaliado, é uma complicação da otite média, bem descrita na literatura, e se explica pela proximidade anatômica do nervo facial ao osso temporal ${ }^{(8)}$. Em relação à paresia bilateral assimétrica do IV nervo, o diagnóstico foi feito através de exame oftalmológico minuncioso, o qual revelou além da paresia do músculo oblíquo superior direito, paresia discreta do músculo oblíquo esquerdo. Conforme relação cronológica entre o aparecimento da otite média à $\mathrm{D}$, sua evolução desfavorável, com paresia do nervo facial, e o posterior achado arteriográfico da trombose do seio tranverso à $\mathrm{D}$, acredita-se que a paresia bilateral assimétrica do nervo troclear seja uma complicação relacionada ao mesmo processo infeccioso.

$\mathrm{O}$ diagnóstico da bilateralidade de acometimento do troclear é dado pela inversão da HT em lateroversões: D/E à esquerda e E/D à direita, podendo haver paralelismo em frente. A explicação para a bilateralidade da paresia troclear encon- trada em nosso paciente, é possivelmente devido à trombose venosa estar localizada próxima ao local de emergência dos nervos no tronco encefálico ${ }^{(3)}$.

Após extensa revisão bibliográfica da literatura nacional e internacional, não se encontrou relato semelhante ao descrito. Desta forma, os autores enfatizam a importância deste caso como a primeira descrição de paresia troclear associada a trombose de seio transverso, sem evidências de meningite basilar ou trombose de seio cavernoso concomitante.

\section{ABSTRACT}

The authors describe a case of a 30 year old, male patient, with acute otitis media after timpanic perforation, progressing with left transverse sinus thrombosis, right facial palsy of central origin and asymmetric bilateral trochlear palsy. The ophthalmologic examination showed SO hypofunction and IO hyperfunction in both eyes, although more markedly in the right eye. There was a positive Bielschowsky sign to the right. Vision was preserved, and there was no papilledema. The cerebral angiography showed left transverse sinus thrombosis, without any concomitant anomaly. The patient was treated with oral antibiotics and a coumarinic drug. After six months, diplopia was present only in leftdowngaze. The facial palsy was still present. No similar report was found in the literature.

Keywords: Palsy; Troclear nerve/pathology; Sinus thrombosis intracranial; Case report

\section{REFERÊNCIAS}

1. Samuel J, Fernandes CMC. Lateral sinus thrombosis (a review of 45 cases). J Laryngol Otol 1997;101:1227-9.

2. Singh B. The management of lateral sinus thrombosis. J Laryngol Otol 1993;107:803-8.

3. Southwick FS, Richardson EP Jr, Swartz MN. Septic thrombosis of the dural venous sinuses. Medicine (Baltimore) 1986;65:82-106.

4. Deric D, Arsovic N, Dorcevic V. Pathogens and methods or treatment of otogenic brain abscess. Med Tregl 1998;51:51-5.

5. Younge BR, Stula F. Analysis of trochlear nerve palsies - Diagnosis, etiology and treatment. Mayo Clin Proc 1977;52:11-7.

6. Walsh FB. Clinical neuro-ophthalmology. Baltimore: Williams, Wilkins, 1957.

7. Souza-Dias C; Prieto-Diaz J. Estrabismo. 3a ed. São Paulo:Roca; 1996. 393p.

8. Portmann M. Manual de otorrinolaringologia. São Paulo: Masson; 1983. 332p.

\section{Novidades na Internet!!!}

Agora no site CBO você tem disponível todas as informações na íntegra dos Arquivos Brasileiros de Oftalmologia http://www.cbo.com.br/abo 